\title{
Examination Subclinical Inflammatory Markers and Plasma Neutrophil Gelatinase-Associated Lipocalin in Obsessive-Compulsive Disorder
}

\author{
Kader Semra Karatas (Corresponding author) \\ Kutahya Health Science University Medical School, \\ Psychiatry Department, Kutahya/Turkey \\ E-mail: drsemraidil@gmail.com \\ http://orcid.org/0000-0001-6205-7406 \\ Tahsin GokhanTelatar \\ Recep Tayyip Erdoğan University Medical School, \\ Public Health Department, Rize/Turkey \\ E-mail:gokhantelatar@gmail.com \\ http://orcid.org/0000-0002-3261-3464 \\ Ilkay Bahceci \\ Recep Tayyip Erdoğan University Medical School, \\ Medical Microbiology and Clinical Microbiology Department, Rize/Turkey \\ Email:İlkay.bahceci@erdogan.edu.tr \\ http://orcid.org/0000-0003-3662-1629 \\ Bulent Bahceci \\ Recep Tayyip Erdogan University Medical School, \\ Psychiatry Department, Rize/Turkey \\ E-mail:bulentbahceci@hotmail.com \\ https://orcid.org/0000-0002-7591-3643 \\ Cicek Hocaoglu \\ Recep Tayyip Erdogan University Medical School, \\ Psychiatry Department Rize/Turkey \\ E-mail:cicekh@gmail.com \\ https://orcid.org/0000-0001-6613-4317
}

\begin{abstract}
Background: Inflammation has a role in the etiopathogenesis of obsessive-compulsive disorder (OCD).

Aims: We investigated the relationship of disease and disease severity with plasma neutrophil gelatinase-associated lipocalin (NGAL) level, and subclinical hemogram parameters in patients new diagnosed OCD.
\end{abstract}

Methods: A total of 39,654 patients who presented to the ambulant psychiatry outpatient clinic, diagnosed a psychiatric diseases between January 2018 and October 2020 were evaluated DSM-5 criteria; 54 patients who were new diagnosis OCD included in the study. The hemogram was evaluated platelet (PLT) count, PLT-lymphocyte ratio (PLR), PLT- distribution witdth (PDW), neutrophillymphocyte ratio (NLR), C-reactive protein (CRP), and NGAL levels were analyzed in relation to an inflammatory condition.

Results: A significant difference was found between disease severity and the PLT count, PDW, and NGAL values. PDW and NGAL values have relationship with disease severity by linear regression analysis. A significant difference was found the OCD with higher CRP, PDW, and a lower PLT value and showed a relationship between the PDW value by ROC analysis. 
Conclusion: This study was novel in reporting a significant relationship between the PDW level and the disease, and between the PDW and NGAL levels and disease severity in patients diagnosed with OCD.

Keywords: CRP, NGAL, OCD, PDW, platelet count

\section{Special Issue of Health Sciences}

DOI: $10.7176 /$ JSTR/7-08-04

\section{Introduction}

Obsessive-compulsive disorder (OCD) is a mental disorder characterized by impulses, fantasies, or thoughts that recursively enter the person's mind, cannot be expelled by conscious effort, and cause unwanted thoughts, discomfort, and anxiety accompanied by behaviors or mental actions to reduce anxiety (Tamam\&Demirkol, 2019). It is seen nearly equal in men and women, and the lifetime prevalence is between $0.5 \%$ and $3.3 \%$. The age of onset is generally 19 years in men and 22 years in women. However, OCD can also be seen in children (Karataş et al., 2020; Tamam\&Demirkol, 2019). Although some theories about neurotransmitter systems, hormones, neurotrophic factors, and immune system have been proposed regarding etiopathogenesis, its pathophysiology has not been fully elucidated yet (Attwells et al., 2017; Karataş et al., 2020; Tamam\&Demirkol, 2019; Tan et al., 2012; Turgut, 2016). Demonstration of the immunological dimension in OCD occurring in childhood (Gilbert, 2019; Swedo et al., 1998; Tan et al., 2012) and the association of OCD with autoimmune diseases in adulthood (Herdi et al., 2020; Maina et al., 2009) has brought attention to immune regulation. Changes in the levels of acute- and chronic-phase proteins such as anti-streptolysin-O (ASO), antithyroid antibodies, tumor necrosis factor (TNF)- $\alpha$, IL-6, and IL- $1 \beta$ and changes in CD8+ and CD4+ cell count were investigated in OCD, but the role of humoral and cellular immunity was found to be conflicting (Attwells et al., 2017; Karataş et al., 2020; Monteleone et al., 1998; Turgut, 2016).

The neutrophil and PLT counts increase in inflammation, but the lymphocyte count and the platelet distribution width (PDW) value decrease (Koudouovoh-Tripp \&Sperner-Unterweger, 2012; Tzura et al., 2019).The neutrophil-lymphocyte ratio and platelet-lymphocyte ratio indicated inflammation in schizophrenia, depressive disorder, acute mania, anxiety disorder, and OCD, but no consistent results were found(Herdi et al., 2020; Koudouovoh-Tripp \&Sperner-Unterweger, 2012; Kulaks1zoğlu\& Kulaksızoğlu, 2016; Mayda et al., 2016;Mazza et al., 2019; Sunbul et al., 2016).

The varying results in inflammatory etiopathogenesis studies directed researchers to newly studied mediators. The role of neutrophil gelatinase-related lipocalin (NGAL), a recently described acutephase protein involved in humoral immunity, was investigated in the etiopathogenesis of psychiatric disorders (Dekens et al., 2017; Kang et al., 2018; Karataş et al., 2020; Wei et al., 2018). NGAL is a hydrophobic neuromediator of the lipocalin family. It was first identified as a component of the innate immune system that mediated inflammatory activity by binding to chemotactic peptides, leukotrienes, and platelet-activating factor (Magnussson et al., 2012). It is expressed at very low levels in the brain under normal physiological conditions (Altekin\&Kenesar1, 2013). Cell culture experiments showed that NGAL levels increased under stress in different brain cell types in relation to disease severity; it made astrocytes and microglia susceptible to oxidative stress, caused neuron damage, and reflected inflammatory damage to the brain (Altekin\&Kenesarı, 2013; Karataş et al., 2020). Animal experiments showed that NGAL levels increased in the hippocampal region of mice exposed to psychological stress (Dekens et al., 2017; Kang et al., 2018; Wei et al., 2018). The serum NGAL levels were investigated in schizophrenia, bipolar disorder, anxiety disorders, depressive disorder, and OCD. Although it was emphasized that NGAL might serve as a marker of schizophrenia, it could not be associated with disease and disease severity in OCD (Gouweleeuw et al., 2015; Karataş et al., 2020; Naude et al., 2013; Wei et al., 2018).

Considering the diversity and different results in inflammatory etiology, the present study investigated the relationship of NGAL, serum reactive protein (CRP), another inflammatory marker, and hemogram parameters with disease and disease severity in patients diagnosed with OCD for the first time.

Studies exploring the relationship of NGAL with disease and disease severity in OCD and those evaluating NLR and PLR are limited (Herdi et al., 2020; Karataş et al., 2020); also, no study related to PLT activation has been reported. Because of these gaps in the literature, the present study investigated NLR, PLR, PLT count, PDW, PLT activation, and NGAL level in patients with new diagnosis OCD. 
We believe that changes in these parameters may play a role in the inflammatory etiopathogenesis of OCD, be used as a marker in patients withnew diagnosisOCD, be associated with disease severity, and help in further explorations.

\section{Subjects and Methods \\ Study design}

This was a descriptive epidemiological study.

\section{Population, sample, study protocol, and data collection}

The population in this study consist of 39,654 patients diagnosed with a psychiatric diseases who presented to the ambulant psychiatry outpatient clinic between January 2018 and October 2020. According to computer records, 560 OCD patients were found between January 2018 and August 2020. Among these patients, 75 were received a new diagnosis OCD. The patients were contacted via phone and informed about the study.A total of 49 patients who met the following inclusion criteria were included in the study: patients who did not receive regular psychiatric treatment, patients who still had OCD symptoms, patients who did not have any other psychiatric disease, patients who did not have any systemic disease such as an autoimmune, neurological, cardiovascular, physical, or endocrinological disease, patients who did not use medications regularly, for any reason, and patients who agreed to participate.

After the psychiatric interviews held between August 2020 and October 2020, 20 patients were diagnosed with OCD and 7 patients who met the inclusion criteria and new diagnosis OCD were identified. Of these, 5 agreed to participate in the study. The other two did not want to participate in the study and were therefore excluded. Thus, the study was conducted with 54 patients, retrospectively and prospectively.

The people in the control group were selected from among those who applied to the psychiatry outpatient clinic between August 2020 and October 2020 for reasons such as health certificates for job applications and driving license renewal.People who were not diagnosed with any psychiatric disease; did not have a systemic disease such as an autoimmune, neurological, cardiovascular, physical, or endocrinological disease; did not use medications regularly, for any reason; and agreed to participate in the study were included in the control group. The control group consisted of 25 people.

All patients and control groups were included the study after written consent was obtained.

\section{Protocol of study}

Interviews lasting 30 to $45 \mathrm{~min}$ were conducted in the clinic room with 54 patients who agreed to participate in the study. In the first part of the interview, a sociodemographic data form was prepared by the researchers and the Y-BOCS were administered. In the second part, which was carried out on the same day, about $2 \mathrm{pm}, 5 \mathrm{~mL}$ of venous blood was taken from each patient by the same laboratory worker to determine the hemogram and CRP levels in the microbiology laboratory under sterile conditions.

\section{Laboratory parameters}

Under sterile conditions, $5 \mathrm{~mL}$ of venous blood was collected, placed in purple-capped tubes containing EDTA as the anticoagulant, and centrifuged at $4000 \mathrm{rpm}$ for 10 to $15 \mathrm{~min}$. The obtained plasma was placed in Eppendorf tubes and stored at $-20^{\circ} \mathrm{C}$ until the time of analysis. The plasma NGAL level was measured using the manufacturer's recommendations (Plasma lipocalin test kit, Cloud-Clone Corp, TX, USA). The absorbance ratio of each well was determined at $450 \mathrm{~nm}$ using a microtiter plate reader (Multiskan GO, Thermo Scientific, MA, USA) within $5 \mathrm{~min}$. The standard curve was evaluated using the Titri ELISA software. The hemogram was created using a BC-6000/Automatic Hematology Analyzer (Mindray, China) and a CRP Beckman Coulter Au 58000 Automatic Biochemistry Analyzer (Beckman Coulter, USA).

\section{Data collection tools}

Sociodemographic Data Form: This form was prepared by the researchers upon a literature review and used to collect information about the patients diagnosed with new diagnosis OCD. The form included questions on the participants sociodemographic data such as age, sex, marital status, and education level.

Y-BOCS: The Y-BOCS was developed to measure the severity of OCD regardless of the type of obsessions and compulsions and consisted of 19 items. Only the first 10 items are used to determine the 
total score. Clinicians score the items between 0 and 4 . The Turkish validity and reliability study of the scale, which is accepted as a reliable and valid tool to measure symptom severity in OCD, was performed by Karamustafalığlu et al. (Aydemir\&Köroğlu, 2007).

\section{Statistical analysis}

The frequencies of continuous data were presented as mean \pm standard deviation. The distribution of the continuous variables were determined using the Shapiro-Wilk and Kolmogorov-Smirnov tests. The Mann-Whitney $U$ and Kruskal-Wallis tests were used to evaluate the relationships between the variables. A linear regression model was developed with the variables that showed a significant relationship with the Y-BOCS score in a single analysis, and the effects of the variables on the YBOCS score were evaluated together. Also, an ROC curve was drawn to determine the hematological parameters, and the cutoff point and the values of sensitivity and specificity were determined for the variables that show a statistical significance. The statistical significance level was accepted as $\mathrm{p} \leq 0.05$ for all analyses.

\section{Ethics committee approval}

Local ethics committee approval was obtained from the RecepTayyip Erdogan University Faculty of Medicine Non-Interventional Clinical Research Ethics Committee. All applications in this study were made in accordance with the ethical standards of the institutional and/or national research committee and the 1964 Helsinki Declaration and its subsequent revisions, or comparable ethical standards.

\section{Results}

Of the 54 patients diagnosed with OCD, 41 (77.4\%) were women, 13 (22.6\%) were men, 71.4\% were single, $42.9 \%$ were university graduates, and $88.6 \%$ were unemployed. Table 1 shows the comparison of the patient and control groups' sociodemographic characteristics.

Table 1. Comparison of the OCD and control groups sociodemographic characteristics

\begin{tabular}{|c|c|c|c|}
\hline & OCD group & \multicolumn{2}{|c|}{ Control group } \\
\hline Sex & $n(\%)$ & $n(\%)$ & $P$ \\
\hline Male & $13(50.0)$ & $13(50.0)$ & 0.141 \\
\hline Female & $41(77.4)$ & $12(22.6)$ & \\
\hline Marital status & & & \\
\hline Married & $24(64.9)$ & $13(35.1)$ & 0.531 \\
\hline Single & $30(71.4)$ & $12(28.6)$ & \\
\hline Educational status & & & \\
\hline Primary school & $26(78.8)$ & $7(21.2)$ & \\
\hline High school & $25(64.1)$ & $14(35.9)$ & 0.129 \\
\hline University & $3(42.9)$ & $4(57.1)$ & \\
\hline Employment & & & \\
\hline status & & & \\
\hline Employed & $15(42.9)$ & $20(57.1)$ & $<\mathbf{0 . 0 0 1}$ \\
\hline Unemployed & $39(88.6)$ & $5(11.4)$ & \\
\hline
\end{tabular}

OCD: Obsessive Compulsive Disorder, $\mathrm{p}<0.05$, chi-square test

The variables included in linear regression were NGAL, PLT, and PDW. The linear regression analysis showed that NGAL and PDW were blood parameters that affected Y-BOCS in patients with OCD. No statistically significant effect of PLT values on Y-BOCS could be demonstrated (Table 2). 
Table 2. Linear regression analysis of variables affecting the Y-BOCS score

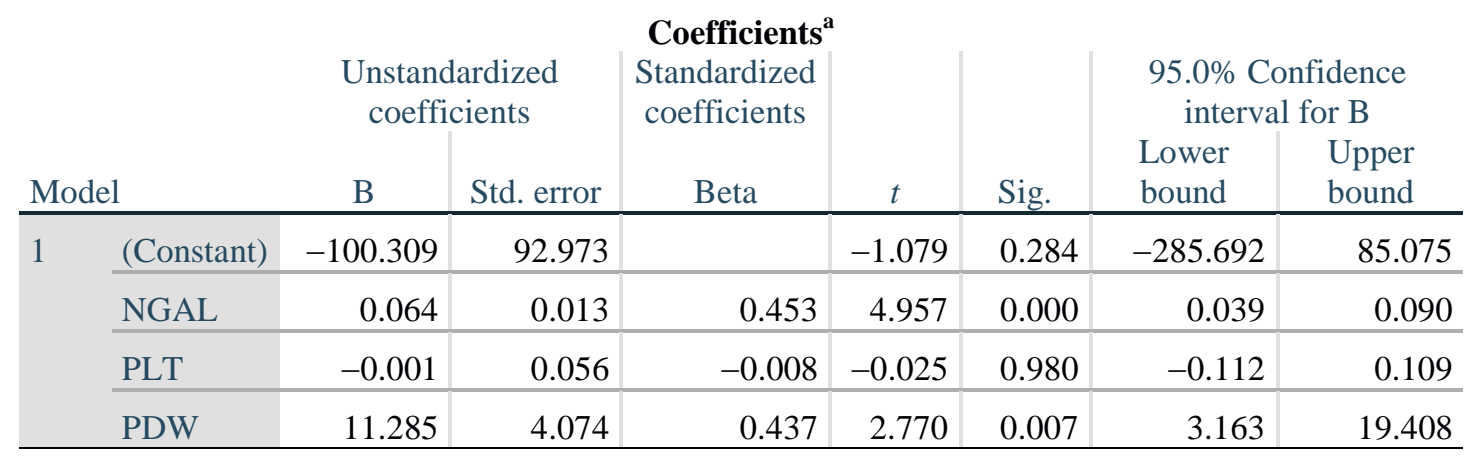

${ }^{\mathrm{a}}$ Dependent variable: Yale Brown Obsessive Compulsive Scale. NGAL: neutrophil gelatinase-associated lipocalin, PLT: platelet, PDW: platelet distribution width.

A significant difference was found between the OCD and control groups with higher CRP, PDW, and a lower PLT value in the OCD group. No significant difference was found between the OCD and control groups NLR and PLR values (Table 3).

In the evaluation of the CRP, PDW, and PLT values to identify the disease using the ROC analysis, the PDW $[P<0.001$, area under the curve $(\mathrm{AUC})=76.7 \%]$, and PLT $(P=0.001, \mathrm{AUC}=26.9 \%)$ values were found to be significant (Figure 1).

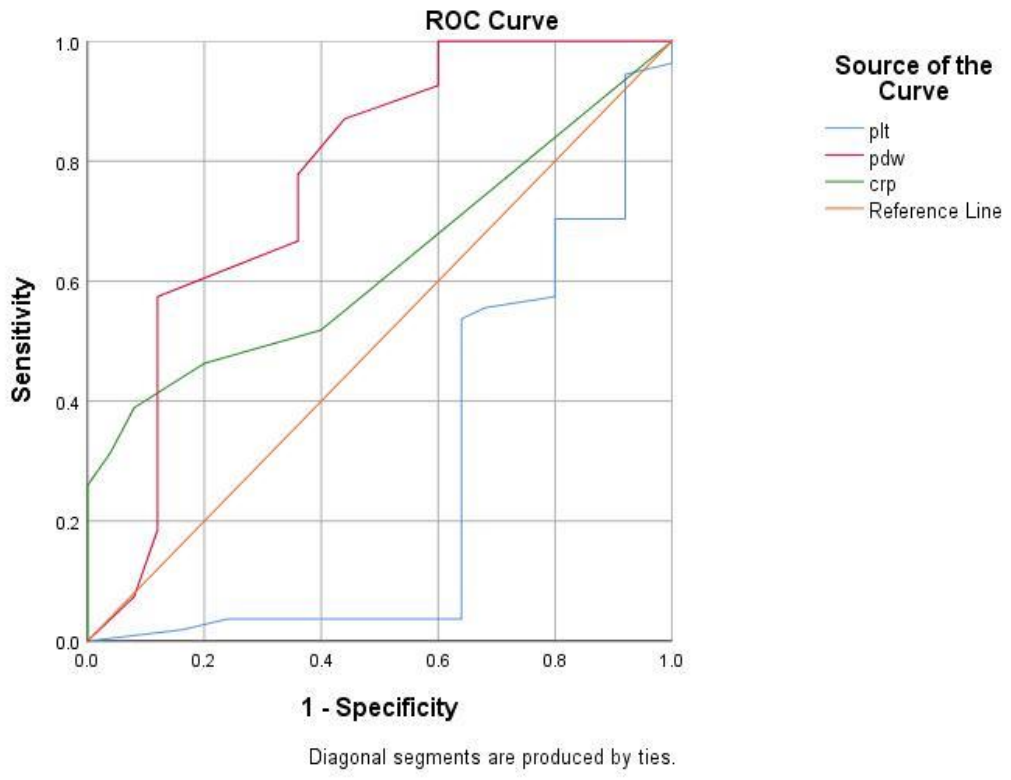

Figure 1.

The AUC was higher than $70 \%$ only for the PDW variable among the variables found to be statistically significant, and the cutoff value for this variable was calculated as 15.85 at $77.8 \%$ sensitivity and $64.0 \%$ specificity. In addition, the ROC curve for screening was drawn to determine the status of the hematological parameters to detect risky cases for other studies.

\section{Discussion}

A comparison between patients new diagnosis OCD and controls showed increased in CRP, PDW values; a decreased in PLT value; and no change in NLR and PLR values. The evaluation of results with ROC analysis revealed a relationship between OCD and the increase in PDW. A relationship was found between Y-BOCS severity and NGAL, PLT, and PDW in these patients. However, a significant difference was noted in the relationship between disease severity and the increase in NGAL and PDW values due to linear regression analysis. 
Table 3. Comparison of all parameters between the OCD and control groups

\begin{tabular}{|c|c|c|c|c|}
\hline \multirow{3}{*}{ NGAL } & Mean & Std. deviation & & \\
\hline & OCD & 231.53 & 89.59 & 0.125 \\
\hline & Control & 198.39 & 85.92 & \\
\hline \multirow{2}{*}{ CRP } & OCD & 1.06 & 2.10 & 0.038 \\
\hline & Control & 0.17 & 0.11 & \\
\hline \multirow[t]{2}{*}{ TLC } & OCD & 7830.74 & 1943.95 & 0.695 \\
\hline & Control & 7986.80 & 538.58 & \\
\hline \multirow[t]{2}{*}{ neu\% } & OCD & 59.47 & 9.76 & 0.796 \\
\hline & Control & 58.88 & 8.46 & \\
\hline \multirow[t]{2}{*}{ Hct } & OCD & 40.58 & 3.92 & 0.396 \\
\hline & Control & 39.90 & 0.96 & \\
\hline \multirow[t]{2}{*}{$\mathrm{Hb}$} & OCD & 13.45 & 1.47 & 0.228 \\
\hline & Control & 13.09 & 0.24 & \\
\hline \multirow[t]{2}{*}{$1 y^{\#}$} & OCD & 2391.30 & 785.80 & 0.827 \\
\hline & Control & 2353.92 & 473.75 & \\
\hline \multirow[t]{2}{*}{$\operatorname{mon}^{\#}$} & OCD & 491.48 & 162.65 & 0.069 \\
\hline & Control & 554.80 & 78.27 & \\
\hline \multirow[t]{2}{*}{ neu\# } & OCD & 4737.41 & 1743.22 & 0.905 \\
\hline & Control & 4782.40 & 1039.11 & \\
\hline \multirow[t]{2}{*}{$\mathrm{eo}^{\#}$} & OCD & 168.52 & 154.19 & 0.400 \\
\hline & Control & 102.00 & 57.66 & \\
\hline \multirow[t]{2}{*}{$\mathrm{ba}^{\#}$} & OCD & 32.04 & 13.79 & 0.157 \\
\hline & Control & 36.40 & 9.52 & \\
\hline \multirow[t]{2}{*}{ ly $\%$} & OCD & 31.38 & 8.77 & 0.073 \\
\hline & Control & 27.75 & 7.02 & \\
\hline \multirow[t]{2}{*}{ mon $\%$} & OCD & 6.50 & 1.45 & 0.171 \\
\hline & Control & 6.91 & 0.50 & \\
\hline \multirow[t]{2}{*}{ eо $\%$} & OCD & 2.23 & 2.02 & 0.260 \\
\hline & Control & 1.28 & 0.74 & \\
\hline \multirow[t]{2}{*}{ ba $\%$} & OCD & 0.43 & 0.22 & 0.934 \\
\hline & Control & 0.42 & 0.09 & \\
\hline \multirow[t]{2}{*}{ RBC } & OCD & 4642.41 & 423.59 & 0.754 \\
\hline & Control & 4613.00 & 286.59 & \\
\hline \multirow[t]{2}{*}{$\mathrm{MCV}$} & OCD & 87.48 & 3.94 & 0.330 \\
\hline & Control & 86.43 & 5.32 & \\
\hline \multirow[t]{2}{*}{$\mathrm{MCH}$} & OCD & 28.97 & 1.52 & 0.580 \\
\hline & Control & 28.18 & 2.01 & \\
\hline \multirow[t]{2}{*}{ MCHC } & OCD & 33.11 & 0.88 & 0.250 \\
\hline & Control & 32.62 & 0.87 & \\
\hline \multirow{2}{*}{ PLT } & OCD & 275.46 & 58.92 & $<0.001$ \\
\hline & Control & 342.16 & 88.49 & \\
\hline \multirow[t]{2}{*}{ MPV } & OCD & 9.51 & 1.02 & 0.527 \\
\hline & Control & 9.37 & 0.51 & \\
\hline \multirow[t]{2}{*}{ PDW } & OCD & 16.15 & 0.34 & $<0.001$ \\
\hline & Control & 15.62 & 0.58 & \\
\hline NLR & OCD & 2.21 & 1.38 & 0.836 \\
\hline & Control & 2.15 & 0.72 & \\
\hline PLR & OCD & 0.06 & 0.03 & 0.194 \\
\hline & Control & 0.07 & 0.02 & \\
\hline
\end{tabular}

OCD: Obsessive Compulsive Disorder, NGAL: neutrophil gelatinase-associated lipocalin, CRP: C-reactive protein, TLC: total leukocyte count, , Hb: hemoglobin, Htc: hematocrit, ly: lymphocyte, mon: monocyte, neu: neutrophil, eo: eosinophil, ba: basophil, ly\%: lymphocyte percentage, mo\% :monocyte percentage, neu \%: neutrophil percentage, eo\%: eosinophil percentage, ba\%: basophil percentage, RBC: red blood cell count, MCV: mean corpuscular volume, MCH: mean corpuscular hemoglobin, MCHC: mean corpuscular hemoglobin concentration, PLT: platelet, MPV: mean platelet volume, PDW: platelet distribution width, NLR: neutrophil-lymphocyte ratio, PLR:PLT-lymphocyte ratio, $\mathrm{p}<0.05$, Mann Whitney-U test. 
Many previous studies stated that CRP could be used as an inflammatory marker that increased in many psychiatric disorders such as schizophrenia, bipolar disease, depressive disorder, and anxiety disorder (Cunha et al., 2008; Huang \& Lin, 2007;Karataş et al., 2020;Mayda et al., 2016; Vismara et al., 2020; Wei et al., 2018). A recent study reported that CRP values increased in patients who were new diagnosis OCD and did not receive any medical treatment (Karataş et al., 2020). Similar results in the present study supported other studies and once again underlined that CRP could be used as a marker that indicated the activation of the inflammatory response system in the etiopathogenesis of OCD.

Inflammatory etiopathogenetic studieson psychiatric diseases emphasized that changes in PLT activity might provide a useful tool for recognizing symptoms, diagnosis, and disease severity (Dekens et al., 2017; Laziera et al., 2001; Magnusson et al., 2012;Ransing et al., 2017). Recent studies stated that PLT activity might be a peripheral indicator in the evaluation of schizophrenia, depressive disorder, psychotic disorder, mood changes, sleep-wake reaction, panic disorder, post-traumatic stress disorder, intrusive thoughts, suicidal attempts, and disease and disease severity; however, the results are conflicting (Camacho \&Dimsdale, 2000;Cicin-Sain et al., 2000;Dietrich-Muszalska\& Wachowicz, 2017; Pivac et al., 2006). PLT activity was shown by PLT count, MPV, and PDW; PDW values changed directly with MPV and inversely with PLT; and PDW was more specific than PLT count and MPV (Asoglu et al., 2016;Laziera et al., 2001;Ransing et al., 2017; Vagdatli et al., 2010). Researchers reported that PDW values higher than $16.7 \%$ increased hospitalization duration and mortality in many diseases with inflammation. They explained this with the release of cytokines and enzymes from activated PLTs, which increase inflammation, deteriorate the immune system, and may increase apoptosis (Camacho \&Dimsdale, 2000; Tzura et al., 2019). The present study found that a decrease in PLT and an increase in PDW value were related to disease and disease severity in patients diagnosed with OCD for the first time, suggesting that PLT activation might serve as a prognostic marker.

Researchers stated that neutrophil and PLT counts increased and lymphocyte count decreased as an indicator of inflammation in psychological stress. NLR and PLR might act as markers in evaluating the etiopathogenesis of psychiatric diseases and could be used in mortality and morbidity studies (Kulaksizoglu\&Kulaksizoglu, 2005; Mazza et al., 2019). NLR and PLR values were evaluated in patients with schizophrenia, bipolar disease, depressive disorder, and suicidal behavior compared with healthy controls and were associated with disease severity and mortality (Kulaksizoglu\&Kulaksizoglu, 2005; Sunbul et al., 2016). NLR and PLR increased in depressive disorder (Cai et al., 2017), and NLR values were high in bipolar disorder (Demircan et al., 2016; Vismara et al., 2020). Studies comparing patients with schizophrenia with controls revealed a significant increase in NLR values (Mazza et al., 2019; Moody \& Miller, 2018). It was examined NLR and PLR in patients with depressive disorder and suicidal behavior and found higher NLR values (GündogduMeydaneri\&Meydaneri, 2018). A recent study showed that NLR and PLR values increased in patients with OCD; despite a relationship between NLR and an equivalent dose of fluoxetine, no correlation was found with PLR. The same study showed that PLR might be a suitable marker in OCD research (Herdi et al., 2020). The present study found no relationship of NLR and PLR values with inflammatory etiopathogenesis or disorder severity in patients diagnosed with OCD for the first time. NLR and PLR, which were studied in many psychiatric disorders and might serve as an indicator of inflammation and mortality, were examined in patients diagnosed with OCD for the first time. However, we believe that it may be appropriate to review the data of our study with larger-sample groups and multicenter studies because our study group was small. The fact that NGAL increases in brain and plasma after psychological stress was shown in both animal studies and human research (Altekin\&Kenesar1, 2013; Kang et al., 2018; Magnusson et al., 2012). One study reported that the plasma NGAL level increased significantly in patients with schizophrenia. The same study found that the plasma NGAL level was lower in patients with depression and anxiety compared with patients with schizophrenia (Wei et al., 2018). Also, the plasma NGAL level increased in depression, regardless of age and antidepressant use, was higher in recurrent depression compared with first-episode depression, and was associated with mortality (Dekens et al., 2017; Naude et al., 2013; Gouweleeuw et al., 2015). Further, NGAL supported the inflammatory activity by binding to the platelet-activating factor and caused neuron damage by increasing sensitivity to oxidative stress (Altekin\&Kenesar1, 2013; Magnusson et al., 2012). A previous study did not find a relationship between disease severity and plasma NGAL level in patients diagnosed with OCD for the first time (Karataş et al., 2020). However, this study, which was conducted with a bigger sample, revealed a significant positive relationship between disease severity and plasma NGAL level. Showing the relationship between NGAL elevation and disease severity in inflammatory etiology research on patients diagnosed with new diagnosis OCD increases the strength of other significant data supporting inflammation. However, including a cost-effective, easy-to-examine parameter such as PLT activity, 
which was also used in this study, in etiopathogenesis studies on psychiatric diseases is more appropriate.

This limitation of this study were that it determined inclusion criteria to minimize confounding factors. Therefore, the size of the sample and control groups decreased.

The strengths of this study were that it used CRP level and PLT activity, which are accepted as inflammatory markers, revealed the significance of NGAL in patients new diagnosis OCD patients, and supported the inflammatory etiopathogenesis of the disease. Another important aspect of the study was the significance of eosinophil count and the examination of NLR and PLR values in patientsnew diagnosis OCD. PLT activity was not evaluated earlier in patientsnew diagnosis OCD, which was an additional advantage of the study. In addition, the study showed the relationship between PDW and disease and disease severity, which increased the value of the study.

Hence, an inexpensive and easy-to-examine parameter such as PLT activity can be used in inflammatory etiopathogenesis studies of OCD. PDW can be used as a marker in evaluating the disease and disease severity in OCD. The findings of this study can provide researchers with another point of view for etiopathogenesis studies on other psychiatric diseases.

There is no conflict of interest.

\section{References}

Altekin, E.,\&Kenesarı, Y (2013). Potansiyel tanısal bir biyo belirteç olarak nötro filjelatinaz ilişkilili pokalin. TürkKlinikBiyokimyaDerg, 11, 37-41. https://tkb.dergisi.org/text.php3

Asoglu, M., Aslan, M., Imre, O., Kivrak, Y., \&Akil, O. (2016). Mean platelet volüme and red cell distribution width levels in initial evaluation of panic disorder. Neuropsychiatr Dis Treat.,12, 2435-2438. https://doi.org/ 10.2147/NDT.S111108

Attwells, S., Setiawan, E., Wilson, A.A., Rusjan, P.M., \&Mizrahi, R. (2017).Inflammation in the neurocircuitry of obsessive-compulsive disorder. JAMA Psychiatry, 74, 833-840. https://doi.org/ 10.1001/jamapsychiatry.2017.1567

Aydemir,Ö.,\&Köroğlu, E. (2007).PsikiyatrideKullanılanKlinikÖlçekler. HekimlerYayınBirliği, Ankara.

Becker, M., Axelrod, D.J., Oyesanmi, O., Markov, D.D., \&Kunkel, E.J. (2007).Hematologic problems in psycho-somatic medicine. PsychiatrClin North Am, 30, 739-759. https://doi.org/ 10.1016/j.psc.2007.07.006

Cai, L., Xu, L., Wei, L., \&Chen, W.(2017). Relationship of mean platelet volüme to MDD: a retrospective study. Shanghai Arch Psychiatry.,29, 21-29. https:// doi.org/10.11919/j.issn.10020829.216082

Camacho, A.,\&Dimsdale, J.E. (2000). Platelets and psychiatry: lessons learned from old and new studies. Psychosom Med, 62, 326-336. https:// doi.org/10.1097/00006842-200005000-00006

Cicin-Sain, L., Mimica, N., Hranilovic, D., Balija, M., \&Ljubin, T. (2000). Posttraumatic stress disorder and platelet serotonin measures. J Psychiatr Res,34, 155-161. https://doi.org/ 10.1016/s0022-3956(99)00049-7.

Cunha, A.B., Andreazza, A.C., Gomez, F.A., Frey, B.N., \&Da Silveira, L.E. (2008). Investigation of serum high-sensitivite C-reactive protein levels across all mood states in bipolar disorder. Eur Arch PssychiatryClinNeurosci,258, 300-304. https:// doi.org/10.1007/s00406-007-0797-0

Dekens, D.W., Naud'e, P.J.W., Engelborghs, S., Vermeiren, Y., \&Dam, D.V. (2017). Neutrophil gelatinase-associated lipocalin and its receptors in Alzheimer's Disease (AD) brain regions: differential findings in AD with and without depression. J AlzheimersDis, 55, 763-776. https:// doi.org/ 10.3233/JAD-160330 
Demircan, F., Gözel, N., Kılınc, F., Ulu, R., \&Atmaca, M. (2016). The Impact of Red Blood Cell Distribution Width and Neutrophil / Lymphocyte Ratio on the Diagnosis of Major Depressive Disorder. NeurolTher, 5, 27-33. https:// doi.org/10.1007/s40120-015-0039-8

Dietrich-Muszalska, A.,\& Wachowicz, B. (2017).Platelet haemostatic function in psychiatric disorders: Effects of antidepressants and antipsychotic drugs. World J Biol Psychiatry, 18, 564 574. https:// doi.org/ 10.3109/15622975.2016.1155748

Gilbert, D.L. (2019). Inflammation in Tic Disorders and Obsessive-Compulsive Disorder:Are PANS and PANDAS a Path Forward?. J. Child Neurol, 34, 598-611. https://doi. org/10.1177/0883073819848635.

Gouweleeuw, L., Eisel, U.L.M., DeJongste, M.J., Eisel, U.L., \&Schoemaker, R.G. (2015). The role of neutrophil gelatinase associated lipocalin (NGAL) as biological constituent linking depression and cardiovascular disease. Brain Behav Immun., 46,23 -32. https://doi.org/ 10.1016/j.bbi.2014.12.026

Gurok, M.G., Yılmaz, S., Temizkan, A., Ustundag, B., \&Atmaca, M. (2019). Levels of basophils and eosinophils are elevated while lymphocytes are reduced in patients with panic disorder compared to controls: a preliminary study. Psychiatry Clin Psychopharmacol., 29, 315-319. https:// doi.org/10.1080/24750573.2018.1478191

GundogduMeydaneri, G.,\& MeydanerI, S. (2018).Can Neutrophil Lymphocyte Ratio Predict the Likelihood of Suicide in Patients with Major Depression? Cureus10:e2510. https:// doi.org/10.1007/s00384-012-1459-x.

Herdi, O., SayarAkaslan, D., İlhan, R.S., \&Çolak, B. (2020). Associations Between Subclinical Inflammatory Markers and OCD: A Retrospective Study. Pychiatry Research, 290, 113065. https:// doi.org/ 10.1093/ajcn/85.6.1615

Huang, T.L.,\& Lin, F.C. (2007). High-sensitivity C-reactive protein levels in patients with major depressive disorder and bipolar mania. ProgNeuropsychopharmacolBiol Psychiatry, 31, 370372. https:// doi.org/10.1016/j.pnpbp.2006.09.010

Kang, S.S., Ren, Y., Liu, C.C., Kurti, A., \&Baker, K.E. (2018). Lipocalin-2 protects the brain during inflammatory conditions. Mol Psychiatry, 23, 344-350. https:// doi.org/ 10.1038 /mp.2016.243

Karataş, K.S., Bahçeci, İ., Telatar, T.G., \&Bahçeci, B. (2020). Obsesifkompulsif bozuklukta plazma nötro filjelatinaz ilişkilili pokalin ve hemogram düzeyleri ile hastalık şiddeti arasındaki ilişki. Anadolu Psikiyatri Derg., 21, 585-591.http://doi.org/10.5455/apd.92234

Koudouovoh-Tripp, P.\&Sperner-Unterweger B. (2012). Influence of mental stress on platelet bioactivity. World J Psychiatr, 2, 134-147.https://doi.org/10.5498/wjp.v2.i6.134

Kulaksizoglu, B.,\&Kulaksizoglu, S. (2016). Relationship between neutrophil/lymphocyte ratio with oxidative stres and psychopathology in patients with schizophrenia. Neuropsychiatr Dis Treat., 12, 1999-2005.https://doi.org/10.2147/ndt.s110484

Laziera, K., Chowa, E.W.C., AbdelMalika, P., Scutta, L.E., \&Weksbergc, R. (2001). Low platelet count in a 22q11 deletion syndrome subtype of schizophrenia. Schizophr Res., 50, 177-180. https://doi.org/10.1016/s0920-9964(00)00159-6

Magnusson, N.E., Hornum, M., Jorgensen, K.A., Hansen, J.M., \&Bistrup, C. (2012). Plasma neutrophil gelatinase associated lipocalin (NGAL) is associated with kidney function in uraemic patients before and after kidney transplantation. BMC Nephrol.,13, 8. https://doi. org/10. $1186 / 1471-2369-13-8$ 
Maina, G., Albert, U., Bogetto, F., Borghese, C., \&Berro, A.C. (2009). Anti-brain antibodies in adult patients with obsessive-compulsive disorder. J Affect Disord, 116, 192-200. https://doi.org/10.1016/j.jad.2008.11.019

Mayda, H., Ahsen, A., Bağcıoğlu, E., Öztürk, A.,\&Bahçeci. B. (2016). Effect of increasedneutrophil-to-lymphocyteratio (NLR) and decreased mean platelet volume (MPV) values on Inflammation in acute mania. Arch Neuropsychiatry, 53, 317-320. https://doi.org/10.5152/npa.2016.10272

Mazza, M.G., Lucchi, S., Tringali, A.G.M., Rossetti, A.,\&Botti, E.R. (2019). Neutrophil/lymphocyte ratio and platelet/lymphocyte ratio in mood disorders: a meta-analysis. Prog Neuro-PsychopharmacolBiol Psychiatry, 84, 229-236. https://doi. org/10.1016 /j.pnpbp.2018.03.012

Moody, G.,\& Miller, B.J. (2018). Total and Differential White Blood Cell Counts and Hemodynamic Parameters in First-EpisodePsychosis. Psychiatry Res, 260, 307-312. https://doi.org/10.1016/j.psychres.2017.11.086

Monteleone, P., Catapano, F., Fabrazzo, M., Tortoella, A., \&Maj, M. (1998). Decreased blood levels of tumor necrosis factor-alpha in patients with obsessive-compulsive disorder. Neuropsychobiology, 37, 182-185. https://doi.org/10.1159/000026500

Naudé, P.J.W., Eisel, U.L.M., Comijs, H.C., Groenewold, N.A., \&De Deyn, P.P. (2013). Neutrophil gelatinase-associated lipocalin: a novel in flammatory marker associated with late-life depression. J. Psychosom. Res., 75, 444-450. https://doi.org/10.1016/j.jpsychores.2013.08.023

Pivac, N., Kozaric-Kovacic, D., Mustapic, M., Dezeljin, M., \&Borovecki, A. (2006). Grubisic-Ilic $\mathrm{M}$ et al.: Platelet serotonin in combat related posttraumatic stress disorder with psychotic symptoms. J Affect Disord, 93, 223-227. https://doi.org/10.1016/j.jad.2006.02.018

Ransing, R.S., Patil, B., \&Grigo, O. (2017). Mean platelet volume and platelet distribution width level in patients with panic disorder. J Neurosci Rural Pract., 8, 174-178. https://doi.org/10.4103/jnrp.jnrp_445_16

Rasmussen, S.A.,\&Eisen, J.L. (1994). The epidemiology and differential diagnosis of obsessivecompulsive disorder. J Clin Psychiatry., 55, 5-10. https://pubmed.ncbi.nlm.nih.gov/7961532/

Ross, D.C., Preter, M., \&Klein, D.F. (2001). Hematologic alterations and CO2 hypersensitivity in male panic disorder patients and normal controls: similarities to high-altitude hypoxia and chronic lung disease. Depress Anxiety., 14, 153-154. https://doi.org/10.1002/da.1059

Sunbul, E.A., Sunbul, M., Yanartas, O., Cengiz, F., \&Bozbay, M. (2016). Increased Neutrophil/Lymphocyte Ratio in patients with depression is correlated with the severity of depression and cardiovascular risk factors. Psychiatry Investig., 13, 121-126. http://doi.org/10.4306/pi.2016.13.1.121

Swedo, S.E., Leonard, H.L., Garvey, M., Mittleman, B., \&Allen, A.J. Pediatric autoimmune neuropsychiatric disorders associated with strep-tococcal infections: clinical description of the first 50 cases. Am J Psychiatry, 155, 264-271. https://doi.org/10.1176/ajp.155.2.264

Tan, J., Smith, C.H.,\& Goldman, R.D. (2012). Pediatric autoimmune neuropsychiatric disorders associated with streptococcal infections. Can. Fam. Physician 2012. https://doi org/10. 1176/ foc.2.3.496.

Tamam, L.,\&Demirkol, M.E. (2019).Obsesif Kompulsif Bozukluk ve İlişkili Bozukluklar. Bütüncül Tıp: Birinci Basamakta ve Aile Hekimliğinde Güncel Tanı-Tedavi. Nobel Tıp Kitabevleri, Ankara. 
Turgut, K.,\&Ak, M. (2016).Obsesifkompulsif bozukluk ve biyokimya. Turkiye Klinikleri J Psychiatry-Special Topics, 9, 15-22. https://www.turkiyeklinikleri.com/article/tr

Tzur, I., Barchela, D., Izhakiana, S., Swarkaa, M., \&Garach-Jehoshua, O. (2019). Platelet distribution width: a novel prognostic marker in an internal medicine ward. J Community Hosp Intern Med Perspect., 9, 464-470. https://doi.org/10.1080/20009666.2019.1688095

Vagdatli, E., Gounari, E., Lazaridou, E., Katsibourlia, E., \&Tsikopoulou, F.(2010). Platelet distribution width: A simple, practical and specific marker of activation of coagulation. Hippokratia., 14, 28-32. http://www.ncbi.nlm.nih.gov/pmc/articles/pmc2843567

Vismara, M., Girone, N., Cirnigliaro, G., Fasciana, F., \&Vanzetto, S. (2020). Peripheral Biomarkers in DSM-5 Anxiety Disorders: An Updated Overview. Brain Sci., 10, 1-37. https://doi.org/10.3390/brainsci10080564

Wei, L., Du, Y., Wu, W., Fu, X., \&Xia, Q. (2018). Elevation of plasma neutrophil gelatinaseassociated lipocalin (NGAL) levels in schizophrenia patients. J AffectDisord, 226, 307-312. https://doi.org/10.1016/j.jad.2017.10.002 